\title{
Frequency dependent sympathetic modulation of vasomotor tone in the anesthetized rat
}

\author{
M.L. Tsai ${ }^{\mathrm{a}, \mathrm{b}}$, L.W. Chu ${ }^{\mathrm{c}}$, C.Y. Chai ${ }^{\mathrm{b}}$, C.-T. Yen ${ }^{\mathrm{a}, *}$ \\ ${ }^{a}$ Department of Zoology, National Taiwan University, \#1, Section 4, Roosevelt Road, Taipei, 10764 Taiwan, ROC \\ ${ }^{\mathrm{b}}$ Institute of Biomedical Sciences, Academica Sinica, Taipei, Taiwan, ROC \\ ${ }^{\mathrm{c}}$ Institute of Electric Engineering, National Taiwan University, Taipei, Taiwan, ROC
}

Received 21 October 1996; revised version received 2 December 1996; accepted 4 December 1996

\begin{abstract}
The hypothesis that sympathetic nerve system modulates a specific frequency range of blood pressure fluctuation was tested by electrical stimulation of the medullary sympathetic excitatory sites in anesthetized, paralyzed, vagotomized, cardiac sympathetic blocked, baroreceptor transected and angiotensin II converting enzyme inhibited rats. The frequency tested ranged from 0.02 to 1.7 Hz. For blood pressure fluctuation within this range there was no specific sympathetic reactive zone. Instead, low frequency fluctuation of sympathetic flow produced blood pressure fluctuation of the same frequency. Transfer magnitude of renal sympathetic activity to blood pressure decrease logarithmically with the increase of stimulation frequency. The relationship between the sympathetic spectral

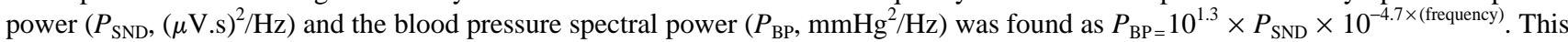
transfer function demonstrates that when blood pressure fluctuation is used to estimate the sympathetic activity, it should be frequency weighted. (C) 1997 Elsevier Science Ireland Ltd. All rights reserved
\end{abstract}

Keywords: Blood pressure fluctuation; Power spectral analysis; Rat, Sympathetic activity; Vasomotor tone

Spectral power of blood pressure at a frequency range slower than the respiratory rate, defined either as low frequency or mid-frequency by previous investigators, has been proposed as a specific marker of sympathetic modulation of the vasomotor tone $[9,10]$. However, a consensus on the range of this frequency band has not been established. For example, in rats, $0.1-0.18 \mathrm{~Hz}$ [1], $0.27-$ $0.74 \mathrm{~Hz}[3,8], 0.38-0.45 \mathrm{~Hz}$ [4], 0.1-0.6 Hz [5], 0.3-0.6 $\mathrm{Hz}$ [6], 0.02-0.605 Hz [7], 0.25-0.75 Hz [11], 0.15-0.6 $\mathrm{Hz}$ [12], $0.2-0.8 \mathrm{~Hz}$ [13], $0.25-0.8 \mathrm{~Hz}$ [15] or exactly at $0.4 \mathrm{~Hz}$ [2], have all been suggested. This makes comparison of the results from different studies difficult. To understand the precise range of frequency in which blood pressure fluctuation can be modulated by sympathetic activity, a logical approach would be to separate the vascular sympathetic action from other factors at work on the cardiovascular system, and to examine its

\footnotetext{
* Corresponding author. Tel.: +8862 3630231, ext. 3322; fax: +8862 3636837.
}

effect in isolation. In this study, we forced the sympathetic activity to fluctuate at various frequencies with electrical stimulation of sympathoexcitatory areas of the medullary oblongata of anesthetized, paralyzed, vagotomized, cardiac sympathetic blocked, baroreceptor denervated and angiotensin II converting enzyme inhibited rats. A transfer function was calculated for the fluctuations of renal sympathetic activity and blood pressure.

Six male Wistar rats (380-450 g) were used. Each rat was anesthetized with sodium pentobarbital $(50 \mathrm{mg} / \mathrm{kg}$, i.p. initially and $12.5 \mathrm{mg} / \mathrm{kg}$ i.v., supplemented as necessary during surgery and every $30 \mathrm{~min}$ during recording period). Femoral artery and vein and trachea were cannulated. These were used for systemic arterial blood pressure recording, drug administration and positive pressure ventilation, respectively. During the recording period the endexpiratory $\mathrm{CO}_{2}$ concentration was maintained between $3.5-4.0 \%$. Rectal temperature was maintained at $37.5 \pm 0.1^{\circ} \mathrm{C}$ with a feedback controlled thermal blanket.

The left kidney was exposed retroperitoneally and the 
renal nerve was dissected free from the surrounding connective tissues and crushed distally. A bipolar hook electrode made of stainless steel microwires (biomedical wire AS 634, Cooner wire Co.; Chatsworth, CA, USA) was positioned under the renal nerve. The exposed nerve and electrode were encased in silicon gel (Wacker Siligel 604; Munich). Baroreceptor denervation was performed which included severing the carotid sinus nerves, glossopharyngeal nerves, superior laryngeal nerves, and sympathetic trunks near the superior cervical ganglia. The carotid bifurcations were stripped of fibers and connective tissues and both vagi were cut near their entrance into the skull. The completeness of the baroreceptor denervation was confirmed by the disappearance of the cardiac rhythm in spectrum of the sympathetic activity and the elimination of the reflex inhibition of heart rate and sympathetic nerve activity during phenylephrine $(5 \mu \mathrm{g} / \mathrm{kg}$, i.v.) induced arterial pressure increase [16].

The head of the rat was fixed in a stereotaxic apparatus in the prone position with the bite bar $10 \mathrm{~mm}$ below the interaural line. The dorsal surface of the medullary oblongata was exposed with the obex as the reference landmark. At this time, gallamine $(50 \mathrm{mg} / \mathrm{kg})$, atenolol $(1 \mathrm{mg} / \mathrm{kg})$ and captopril $(10 \mathrm{mg} / \mathrm{kg})$ were injected, i.v. Supplementary dosages were administered every $10-15 \mathrm{~min}$ in the amounts of one fourth of the initial dosage. A bipolar stimulation electrode was lowered into the medullary oblongata. This was a 3-prong electrode, each separated by $500 \mu \mathrm{m}$ and composed of a glass-insulated microwire [14]. Two of the tips were the anode and the cathode, respectively. The other tip was connected to the electrical ground. This arrangement enabled us to record artifactfree sympathetic activity during stimulation periods (Fig. 1 , inset). The area stimulated included a cubic space which included an area $2.0 \mathrm{~mm}$ rostral to $2.0 \mathrm{~mm}$ caudal to obex, $0-2.0 \mathrm{~mm}$ lateral to the midline, and $0.5-2.5 \mathrm{~mm}$ dorsal to the ventral surface of the medulla. When a sympathoexcitatory point was found, trains of electrical pulses were used to activate the sympathetic nervous system (Anapulse stimulator model 302-T, WPI Inc., New Haven, CT, USA). Parameters of the stimulation were: pulse duration, $500 \mu \mathrm{s}$; pulse intensity, 10-50 $\mu \mathrm{A}$; pulse frequency, $50 \mathrm{~Hz}$; and train duration, $500 \mathrm{~ms}$. Inter-train interval varied from 0.6 to $50 \mathrm{~s}$. The total period of stimulation was $80-90 \mathrm{~s}$. When the blood pressure and renal nerve activity returned to a steady state, the stimulation was repeated. After the last stimulation-recording period, hexamethonium bromide $(20 \mathrm{mg} / \mathrm{kg}$, i.v.) was given to determine the baseline value of renal nerve activity.

Chemicals used were obtained from the following sources: gallamine triethiodide, captopril, atenolol, hexamethonium bromide and 1 -phenylephrine from Sigma Chemical Co. (St. Louis, MO, USA); sodium pentobarbital from Abbott Labs. (North Chicago, IL, USA)

The blood pressure signal was obtained through a pressure-voltage transducer (Gould P23 ID) and amplified
(Grass 7D). The electrical signal of renal nerve was band-pass filtered between 30 and $3 \mathrm{kHz}$ and amplified 10000 times by a Grass P511 differential amplifier. All signals were stored on a tape recorder (model DR-886, Neuro Data, NY, USA). For off-line power spectral analysis, $64 \mathrm{~s}$ analysis period was used. The signals were digitized at $6 \mathrm{~K}$ samples/s using a MP $100 \mathrm{~A} / \mathrm{D}$ converter (BIOPAC System, Inc., Goleta, CA, USA). Renal nerve signals were integrated by a digital integrator with a $20 \mathrm{~ms}$ reset time. The digitized blood pressure and integrated nerve activity signals were resampled at $128 \mathrm{~Hz}$. Power spectral densities of nerve activity and blood pressure were computed by fast Fourier transform (Matlab 4.2c.1, MathWorks, Inc., MA, USA) after removing DC component and applying a Hanning window.

Sympathetic discharge patterns and the corresponding fluctuations of blood pressure during control and three different stimulation periods are shown in Fig. 1. A close coupling between blood pressure and sympathetic activity spectral peaks was observed at low frequency stimulations (Fig. 1B,C) but the blood pressure power corresponding to frequency greater than $1 \mathrm{~Hz}$ was too small to be recognized in this figure (Fig. 1D). In other words, fluctuations of blood pressure followed the sympathetic bursts well during low frequency stimulations but not during higher frequency. Transfer magnitude of sympathetic activity to blood pressure was obtained by dividing the peak value of blood pressure spectral power $\left(P_{\mathrm{BP}}\right)$ to the peak value of sympathetic spectral power $\left(P_{\mathrm{SND}}\right)$ at each stimulation frequency. A plot of the stimulation frequency ( $x$-axis) versus the logarithmic of the transfer magnitude ( $y$-axis) is shown on the upper panel of the Fig. 2. Linear regression analysis revealed a very good fit $(r=0.98 \pm 0.00, n=6)$. The relationship between $P_{\mathrm{BP}}$ and $P_{\mathrm{SND}}$ could be expressed as $P_{\mathrm{BP}}=P_{\mathrm{SND}} \times$ $10^{\text {(intercept) }} \times 10^{\text {(slope) } \times(\text { frequency) }}$ (slope, $-4.72 \pm 0.55$; intercept, $1.26 \pm 0.24, n=6$ ).

The average blood pressure during control was $90.2 \pm 4.5 \mathrm{mmHg}$ and did not vary greatly during periods of electrical stimulation (Fig. 2, lower panel). Many additional factors have been shown to affect blood pressure fluctuation. These include at least: baroreflex, heart rate variability, cardiac contractility, renin-angiotensin system, respiration movement, muscle movement, body posture and body temperature. In this study, the rats' baroreceptors and vagal nerves were removed completely and cardiac sympathetic effects were blocked with a $\beta_{1}$ antagonist, atenolol. The synthesis of angiotensin II was blocked with captopril. The rats were paralyzed throughout the recording period, thus, there were no body movements except chest movements produced by the respirator. All animals were maintained at a steady condition as evidenced by the constant blood pressure, expiratory $\mathrm{CO}_{2}$ level and rectal temperature. Therefore, the sole source for the fluctuations of the blood pressure could only be ascribed to changes in the vascular sympathetic activities. 


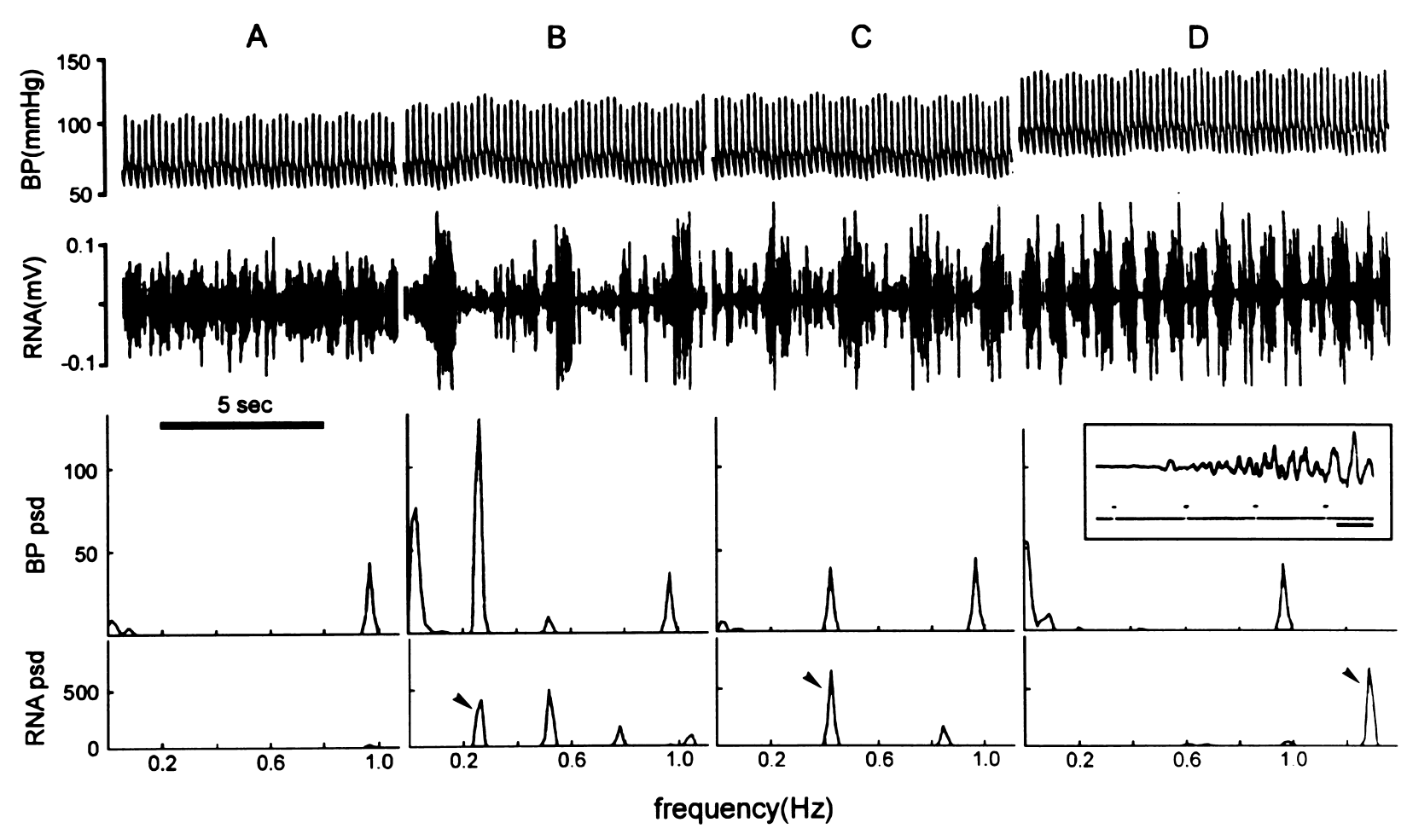

Fig. 1. A representative example of changes in blood pressure (BP), renal nerve activity (RNA) and their respective spectral power (in $\mathrm{mmHg}^{2} / \mathrm{Hz}$ and $(\mu \mathrm{V} . \mathrm{s})^{2} / \mathrm{Hz}$, respectively) during electrical stimulation of the medullary sympathoexcitatory sites with different frequency. (A) Control period with no stimulation; (B) $0.26 \mathrm{~Hz}$; (C) $0.42 \mathrm{~Hz}$; and (D) $1.28 \mathrm{~Hz}$. Arrowheads in lowest panel point to the sympathetic change corresponding to the stimulation frequency. A segment of faster tracing of RNA and stimulator monitor output photographed from the screen of an oscilloscope is shown in the inset of (D). Calibration bar, $10 \mathrm{~ms}$. Note no discernible stimulation artifact in the renal nerve recording.

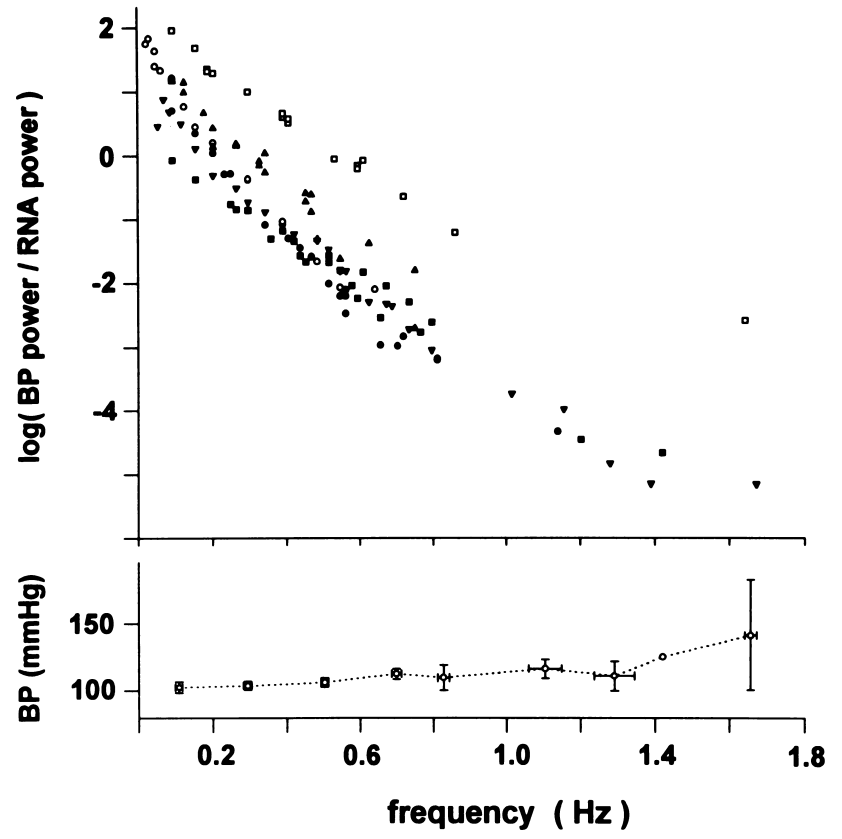

Fig. 2. The upper graph is a plot of the stimulation frequency ( $x$-axis) versus the logarithmic of the transfer magnitude (y-axis). Each point represents one $64 \mathrm{~s}$ electrical stimulation period. Each symbol represents an individual rat $(n=6)$. The lower graph is the averaged blood pressure during these electrical stimulation periods. Values are means \pm SE. Note that blood pressure remained relatively constant with stimulation frequency less than $1.4 \mathrm{~Hz}$.
With this simple system, we demonstrated that a low frequency fluctuation of sympathetic outflow would produce blood pressure fluctuation of the same frequency. We also observed that the sympathetic effect was too sluggish to mediate high frequency $(\geq 1 \mathrm{~Hz})$ variations in blood pressure. The blood pressure response to the sympathetic stimulation decreased exponentially when the stimulation frequency was increased. Results shown in Fig. 2 indicate that there is no specific low frequency band by which sympathetic output prefers to act on the vasculature system. In addition, even if there should be a frequency range of blood pressure fluctuation that could be used as a marker of the sympathetic activity, its spectral power should be frequency weighted.

The authors thank Professor S.H. Ngai of Columbia University for reading the manuscript and advice. This study was supported by a grant NSC 86-2314-B002095-M04 from the National Science Council, ROC.

[1] Akselrod, S., Eliash, S., Oz, O. and Cohen, S., Hemodynamic regulation in SHR: investigation by spectral analysis, Am. J. Physiol., 253 (1987) H176-H183.

[2] Brown, D.R., Brown, L.V., Patwardhan, A. and Randall, D.C., Sympathetic activity and blood pressure are tightly coupled at $0.4 \mathrm{~Hz}$ in conscious rats, Am. J. Physiol., 267 (1994) R1378R1384. 
[3] Cerutti, C., Barres, C. and Paultre, C., Baroreflex modulation of blood pressure and heart rate variabilities in rats: assessment by spectral analysis, Am. J. Physiol., 266 (1994) H1993-H2000.

[4] Cerutti, C., Gustin, M.P., Paultre, C.Z., Lo, M., Julien, C., Vincent, M. and Sassard, J., Autonomic nervous system and cardiovascular variability in rats: a spectral analysis approach, Am. J. Physiol., 261 (1991) H1292-H1299.

[5] Daffonchio, A., Franzelli, C., Radaelli, A., Castiglioni, P., Di Rienzo, M., Mancia, G. and Ferrari, A.U., Sympathectomy and cardiovascular spectral components in conscious normotensive rats, Hypertension, 25 (1995) 1287-1293.

[6] Janssen, B.J.A., Oosting, J., Slaaf, D.W., Persson, P.B. and Struijker-Boudier, H.A.J., Hemodynamic basis of oscillations in systemic arterial pressure in conscious rats, Am. J. Physiol., 269 (1995) H62-H71.

[7] Japundzic, N., Grichois, M.-L., Zitoun, P., Laude, D. and Elghozi, J.-L., Spectral analysis of blood pressure and heart rate in conscious rats: effects of autonomic blockers, J. Autonomic Nerv. Syst., 30 (1990) 91-100.

[8] Julien, C., Zhang, Z.-Q., Cerutti, C. and Barrès, C., Hemodynamic analysis of arterial pressure oscillations in conscious rats, J. Autonomic Nerv. Syst., 50 (1995) 239-252.

[9] Malliani, A., Pagani, M. and Lombardi, F., Physiology and clinical implications of variability of cardiovascular parameters with focus on heart rate and blood pressure, Am. J. Cardiol., 73 (1994) 3C9C.
[10] Malliani, A., Pagani, M., Lombardi, F. and Cerutti, S., Cardiovascular neural regulation explored in the frequency domain, Circulation, 84 (1992) 482-492.

[11] Perlini, S., Giangregorio, F., Coco, M., Radaelli, A., Soldà, P.L., Bernardi, L. and Ferrari, A.U., Autonomic and ventilatory components of heart rate and blood pressure variability in freely behaving rats, Am. J. Physiol., 269 (1995) H1729-H1734.

[12] Persson, P.B., Stauss, H., Chung, O., Wittmann, U. and Unger, T., Spectrum analysis of sympathetic nerve activity and blood pressure in conscious rats, Am. J. Physiol., 263 (1992) H1348-H1355.

[13] Stauss, H.M., Mrowka, R., Nafz, B., Patzak, A., Unger, T. and Persson, P.B., Does low frequency power of arterial blood pressure reflect sympathetic tone, J. Autonomic Nerv. Syst., 54 (1995) 145154.

[14] Tsai, M.L., Chai, C.Y. and Yen, C.-T., A simple method for the construction of a recording-injection microelectrode with glassinsulated microwire, J. Neurosci. Methods, (1996) in press.

[15] Yang, C.C.H., Kuo, T.B. and Chan, S.H.H., Auto- and cross-spectral analysis of cardiovascular fluctuations during pentobarbital anesthesia in the rat, Am. J. Physiol., 270 (1996) H575-H582.

[16] Yang, T.L.-C., Chai, C.Y. and Yen, C.-T., Enhanced sympathetic reactivity to glutamate stimulation in medulla oblongata of spontaneously hypertensive rats, Am. J. Physiol., 268 (1995) H1499H1509. 